\title{
Southeast slope belt sequence stratigraphy and sedimentary facies of pear rift
}

\author{
GUO Shuangting ${ }^{1, \text { a }}$,YUAN Hongqi ${ }^{2, b}$ \\ ${ }^{1}$ Northeast Petroleum University of Daqing City, Heilongjiang \\ province in China \\ ${ }^{2}$ Northeast Petroleum University of Daqing City, Heilongjiang \\ province in China \\ a92902093@qq.com, ${ }^{b} 18131939 @ q q . c o m$
}

\begin{abstract}
Application of sequence stratigraphy theory, utilization of core, log and seismic data, divided the southeast slope with pear rift sequence stratigraphy. The pear rift southeast slope zone is divided into five one sequence (Quantou, Denglouku, Yingcheng, Shahezi, Huoshiling), 10 two sequences (four springs, Quan three sections, K1q2, spring period, Denglouku, four camp, camp three sections, Sec Sha, Sha, Huoshiling), on the basis of sequence stratigraphic units above division and comparison of sedimentary facies and sequence stratigraphy of sedimentary facies within the law were studied to identify the main types of sedimentary facies in the study area include lacustrine, fan delta and braided river delta, meandering river with the conclusions of fan delta underwater distributary channel analysis and the oil-rich delta braided river sand body type most favorable to.

Keywords: pear faulted southeast slope belt, stratigraphic division, sedimentary facies.
\end{abstract}

\section{Stratigraphic correlation method}

The main basis of stratigraphic correlation is well combined with based on different levels of earthquake layer standard step by step close comparison. On the basis of lithology, fossil, stable logo layer (layer standard) as the control, using "cycle comparison and hierarchical control" contrast method, guarantee the depositional cycle corresponding to each other at all levels, to determine reservoir group, sandstone, small layer, improve the accuracy of the contrast. In typical Wells as the center, established lithology and electrical marks layer and the auxiliary layer, then calibration, tracking and comparison, from point to line, from line to plane, to fine stratigraphic correlation in all Wells. Choose various standard well accurately horizon calibration, LANDMARK application software, adopts the interactive method, the factory area of seismic data in the $3 \mathrm{~d}$ layer, fault structure interpretation. 


\section{1 the choice of logging curve}

Well logging curve is one of the important data for reservoir research, different types of logging curve characteristics of stratigraphic response. In addition, different regions due to reservoir lithology and mineral composition, fluid properties, log response change is bigger, so should fully before contrast research litho-electric relations, optimizing the contrast curve.

Using well logging curves layer group comparison, in order to avoid uncertainty of geological logging curve represents, selecting rational combination logging sequence is very important. Curve choice should follow the following principles: can clearly reflect the interface of all kinds of rock, the rock reflect the fine the better; Can clearly reflect the characteristics of the combination of lithologic stratigraphic profiles cycle; Can clearly reflect on lithology is stable sedimentary characteristics of the standard layer.

To give priority to with terrigenous clastic sedimentary sand shale profile, natural potential, natural gamma ray and electrical resistivity logging combination and acoustic logging can more clearly reflect the formation rock phase composition and characteristics of cyclicity. But due to the radioactive substances (mainly tuffaceous) in sediments, are sensitive to rock sand content of natural gamma curve, due to the variation in content of radioactive substances, gamma outliers may arise within the sand layer, affect cycle division. Therefore, according to the main characteristics of logging curves (table 4-2), optimizing natural gamma ray, natural potential, lateral depth and acoustic, density, neutron logging curve analysis of cyclicity, determine the south a cycle characteristics. In cycle under the grid control, the use of natural gamma ray, the deep and shallow lateral curve of small layer division. And acoustic time, density and neutron curve can well reflect the different lithology of the strata, can also be used to assist small layer classification comparison.

The contrast is the main application of well logging curve natural potential curve (SP), natural gamma curve (GR), sonic time difference curve (AC) and lateral (LLD/LLS) depth.

\subsection{Establish standard layered profile}

According to the special basin structure, sedimentary environment, first of all, the selection of skeleton section borehole is not uniform, random, but should be combined with seismic profile formation development is relatively complete, tectonic fault affected area of the standard well, use longer standard test well logging section curve combined with seismic data of stratigraphic sequence division, the geological criteria layer and seismic standard unifies, the standard layer in large reservoir characteristics and formation of top and bottom thickness change trends in the area, in the standard layer characteristics on the basis of making comparison; Through a lot of contrast, choose the typical well established standard layers, and then extend outward from the well. Contrast and perfect, found that there are unreasonable places in a timely manner to adjust, horizon calibration is actually throughout the whole process of geological research, and even the whole development process. 
Standard layered profile request horizon development complete, rock characteristics, electrical characteristics in the district representative. According to the analysis of several well for standard section well, on the basis of the original strata division, through the contrast with surrounding well calibration to determine the quantou formation, denglouku group, the city group, shahe subgroups or boundaries, and then on the basis of natural gamma ray, natural potential, acoustic time difference, the resistivity curve subdivision step by step to determine small layers, on the basis of the Wells extend outward.

\subsection{Comparison of strata}

Depending on the degree of stable sedimentary environment to determine the small layer division and contrast, the method of interval of relatively stable sedimentary environment, lithology can contrast method, the method of sedimentary cycle and rhythm method and thickness slice method, sedimentary environment unstable interval is combined with dip Angle on the seismic data, fault development status, and stratigraphic contact relationship into account, using the relative principle of trend for reservoir formation deposition has groups and sandstone. Compare the before you want to make sure mark layer, the logo layer itself is through a lot of contrast. Mark layer refers to the geological characteristics of the obvious, stability of lithology, thickness is not big and small change, regional strata are widely distributed and is easy to identify. According to their specific characteristics, and can be divided into strata lithology, ancient logo layer, electrical signs, etc. As a symbol of layer, can be a rock, or it can be a interface (such as an unconformity surface, etc.), it may be a period of lithology combination. In stratigraphic section, the selected number of strata, can quickly find out the intrinsic relationship between the formation level, for the unified division formation, improve the contrast accuracy, simplify the comparison method is an important means.

The type of logo layer to undertake choosing according to the actual circumstances of the region. When drilling profile comparison, lithologic marks layer and the electrical layer is very important. Choose good electrical mark layer and do a good job in contrast, the key for increasing accuracy of contrast. In addition to satisfying the general conditions of the signs, electrical signs layer shall be clear and stable characteristics of the electric logging curve, and easily distinguished from adjacent layer. Because electrical is a reflection of the lithology, electrical marks tend to lithologic layer is the same.

Nearly source, phase change fast, sand than high lead to stable strata in the study area is not obvious. Due to the complex relationship between sand body cut pile, in addition to the oil layer boundary, no unified signs of stability in the reservoir layer, layer can use different levels mark step by step, combination of phase sequence rule for comprehensive analysis. Level 1 mark layer is generally larger Angle unconformity, identification marking, large scale and wide regional distribution; Secondary mark layer for large-scale lake flood period stable mudstone deposition, or volcanic activity pyroclastic deposits, regional distribution, stable well drill encounter rate $>90 \%$; Tertiary strata is commonly sedimentary system in stable lithological combination or cycle, such as when sex 
is strong, well drilling rate $>60 \%$.

Nearly source, the formation of phase change generally faster than high, sand, concrete in local wellblock contrast, generally implement standard layer hierarchical control, namely in the study area core, drilling, logging and seismic data analysis as the foundation, combined with the seismic synthetic record, a sign of seismic reflection layer, the earthquake is equal for the whole study area key Wells are well - shock calibration, identification of sequence boundary and lake surface, determine the level of standard layer, accurate control of oil-bearing series. Inside the oil-bearing series according to the characteristics of sedimentary base level changes, determine the stability of regional development of lake flooding surfaces and the surface of the sedimentary transformation as a secondary standard layer, oil layer classification. Because of the complex fault block oilfield development near provenance, short provenance sedimentary system, reservoir group, lack of stable secondary standard layer three layer can only find a few auxiliary sign as the following contrast, they have their unique electrical characteristics can be significantly different from adjacent strata, the plane can easily identify and contrast and on a small scale (a few Km2 or several to dozens of development Wells) continuous tracking and lithology is given priority to with powder sandstone and mudstone.

\section{2 build large north-south profile skeleton}

Across the layer interface structure on seismic reflection, logging and logging data have obvious hallmark. Shahezi bottom mostly basal plane Huoshiling or basin, under the Mesozoic strata, is an area cut by tectonic activity eclipse uplift of the basin unconformity formed, corresponding to the seismic reflection interface T5,equivalent to the lower boundary of the Jurassic reflective interface. On the performance of the super-reflective layer phenomenon, reflected energy is generally strong base, the lower part of the clutter - weak reflection or layered - weak reflections. Under the interface is the basement metamorphic shale directly overlying metamorphic basement, which generally represents a mutation mutation surface sedimentary environment, while at the logs also have significant response (Figure 1).

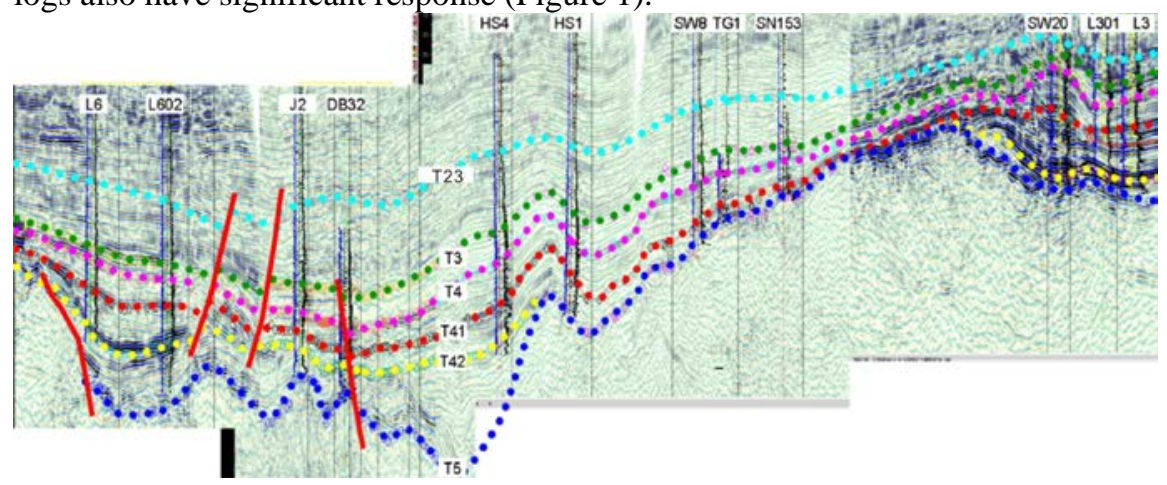

Figure 1 sequence region and even the well seismic profiles 


\section{3 stratigraphic framework of the blocks divided}

\section{1 stratigraphic features Longshan area}

Longshan area is the quality of the block gas production, the main production horizon is Shahezi and Yingcheng, spontaneous potential curve shape is very obvious signs stratified lithology consists of purple and gray mudstone interbedded fine sandstone, by south to north the terrain gradually decreased slowly changing horizon thickness. Thick layer of mudstone K1q2 underside is the region's stability and development developmental level mark layer; Huoshiling also developed a more stable bottom mark mudstone layer; between Denglouku Yingcheng interface with the bottom-up as anti-cyclic to the positive cycle of the interface; QUANTOU and Denglouku interface for a more stable layer of mudstone mark. Overall, Quantou and Denglouku natural potential curve, natural gamma curves and depth of roughly the same magnitude finding form, but there are big Quantou as a secondary set of mudstone caprock, and Denglouku resistance rate curve as a whole was characterized by a high value, sandstone resistivity high volt spike tooth of QUANTOU previous law, Denglouku sandstone teeth of high resistivity spikes. From the lithology of view, there is no Quantou and Denglouku significant lithological change, are brown and gray mudstone interbedded fine sandstone, but Denglouku gray argillaceous siltstone increased.

\section{2 stratigraphic features Jinshan district}

Jinshan district steep terrain, controlled by faults mark layer interface difficult to determine, marking layer tracking difficult. Jinshan region divided sequence, the judge Huoshiling exist annihilate large Denglouku thickness variation, from south to north, gradually thickened. Wide range forecast is not easy to determine the exact wells.

Quantou and Denglouku interface above the most stable flag above the bottom layer is K1q2 are thick mudstone, this interface rather than from the positive cycle, spring for some natural potential, low natural gamma background, depth lateral high value shows that the teeth of the high peaks of the law. Interface below, Denglouku natural potential, natural gamma relatively low Quantou show, compared with the depth of the lateral QUANTOU high value is displayed. From the point of view of lithology, gray and brown mudstone fine sandstone, Denglouku sporadic quartzite. Shahezi interface features and the base is the region's second-largest and most stable marker bed, above the interface peak lateral shades low mutation, large set of quartzite appeared Shahezi show unusually high value of lateral depth and abnormally low spontaneous potential and natural gamma values

\subsection{Heshan regional stratigraphic features}


Heshan Block Block is the focus of this research project, in which the seven trees is the top priority of this project, and the work breakdown layer. Discovery and development of small layer of the main 2,3,5 small layer, you can do further research. Heshan block includes seven wells tree, Qin jiatun two regions, as well as pear main blocks east rift, the two units have different tectonic units, sand body position is not the same group, followed by the specific the sequence analysis.

Judging from the logs, Quantou and Denglouku interface is one of the region's most stable marker bed, from the bottom to the positive cycle of anti-cycle interface, K1q2 thick layer of mudstone remarkable about $300 \mathrm{~m}$. Interface over a period of shades Springs lateral curve of the spike tooth obvious natural potential, low natural gamma display, show the depth of the lateral peak, top Denglouku start subparagraph mudstone, and the rest Denglouku natural potential, natural gamma curve shows the mutant low, high value shades lateral mutation, and there appear negative. From the lithological point of view, no significant changes in the interface down, tan and brown and gray mudstone interbedded fine sandstone, variegated glutenite Denglouku appear. Shahezi with YINGCHENG interface is one of the region's stability symbol layer, the interface below, sand shades Sec peak lateral teeth start of spikes showed good reservoir development.

\subsection{ShuangLong regional stratigraphic features}

ShuangLong area clearly marked stratification, spontaneous potential curve, such as the magnitude of the lateral depth obvious cycle characteristics significantly, but when the effects of different structures, such as the depth of the curve has a different shape, so the sequence stratigraphy of the overall cycle time to pay attention to the similarity of features.Denglouku with YINGCHENG interface is a sign of the region's stable interface,.Denglouku stratigraphic thickness significantly thinner than the other regions, small pieces of sand shale thickness Sec appear as a direct cap, sand Sec still appear teeth of peak values are displayed side shades negative values. From the point of view of lithology, Huoshiling gray-green limestone and green, gray diorite obvious signs. Quantou brownish red mudstone interbedded fine sandstone and gray, and the rest mainly in the gray horizon, dark gray siltstone and mudstone.

\section{4 sedimentary facies types and characteristics}

\section{(1) fan delta}

Provenance fan delta is provided by the alluvial fan, wedge-shaped sedimentary body mainly developed in underwater is alluvial fan depositional systems and water bodies (lakes, sea) developed in activity between (W.Nemec, 1988). Delta fan by fan delta plain, fan delta front and the front fan delta sedimentary facies combinations. An important feature is the fan-delta can be 
deposited on the road, coarse debris underwater gravity flow and the formation of sedimentary traction current symbiosis. Gravity flow deposits often occur in fan delta sedimentary sequences show large numbers of sudden and catastrophic events.

\section{(2) braided river delta}

Braided River Delta is a delta between a normal coarse debris and fine debris fan delta between particularity Delta alone, is one of the most important area of the basin depositional system. Braided river delta in this area is mainly developed in Denglouku deposition of (replaced by his figure); mudstone to gray, gray-green-based, pebbly sandstone gravel braided channel has some sorting, rounded degrees, but sphericity poor, mainly conglomerate, glutenite based.

\section{(3) meandering river with}

Meandering river is the river geomorphology maturity and development, river bend index greater than 1.5, the river is relatively stable in the lateral erosion and processing area dominated. Mainly in the form of suspended load transport, so finer sediment to sediment-based, multi developed in the river downstream. Meandering river sub-phase phase includes bed subphase (riverbed stranded deposition, Sedimentation), bank sub-phase (natural levee deposits crevasse splay deposition), River Man Asian phases, oxbow lake subphase.

\section{(4) lacustrine}

Lakes on the continent is relatively low-lying terrain and water collection areas. According to the flood plane, the dry surface and wave base, the lake into Lake sub-phase phase, shallow lake sub-phase, semi-deep lake and deep lake with phase plane they generally zonal distribution, addition, can be divided into sub-phases Bay. Lakes on the continent with a relatively low-lying terrain and geographical aggregation of water.

\section{Summary}

(1) to sequence stratigraphy theory, the results of a comprehensive study of the seismic study area, drilling, logging and core and other data indicate that pear faulted faulted five-level sequence with the presence of the southeast slope, 10 two sequences.

(2) The body Luo Late Cretaceous to Early meandering main phase, fan delta, braided river delta, lacustrine depositional system.

(3) the trial showed that the conclusions of fan delta oil underwater distributary channel and braided river braided river delta is the most beneficial type of oil-rich sands. 


\section{Acknowledgements}

Thanks Earth Sciences Associate Professor Yuan Hongqi my careful guidance and assistance as well as in academic pointing to me, they thought for flexible academic seriousness and research are worth learning, I insist on the academic path. Here I would like to pay tribute to mentor and heartfelt thanks!

\section{References:}

[1] Chenxian Liang, JI You-liang, Fantai Liang, Wang language, Yan Ning, Chen Xiaoyan Basin pear rift sequence stratigraphic framework and depositional systems of distribution [J]. Geological Journal of China Universities, March 2014, 20 (1 ): 122-130 pages.

[2] There Meng, Li Yong, HE Chuan, and so gentle with sequence stratigraphic model manifold Sag [J] China University of Petroleum (Natural Science), 2011, 35 (4): 14-19.

[3] Chenxian Liang, JI You-liang, Fantai Liang, Wang language, Zhao Man, Nie Wenbin, Chen Xiaoyan, Yan Ning Basin rift pear Sequence Types and development pattern [J]. Central South University (Natural Science), 2014 in April, 45 (4): 1153-1163.

[4] Xuyin Bo, Liu Rong, research Meihe Meihe group Paleogene basin Accumulation and sedimentary evolution of organic matter [J] coal, 2013,38 (11): 2007-2016.

[5] Li Baoyi, Wang Jianpeng, Xuyin Bo, organic-rich mudstone Sunping Chang test parameters and significance rift and sag basin [J] world geological, 2012,31 (4): 778-784.

[6] WANG Guo Shou Qi Qiu, Zhang Xinguo, pear and other Songliao Basin oilfield rift ten houses Yingcheng, Shahezi DIAGENESIS analysis [J] petroleum geology experiment, 2012,34 (5): 474 -480.

[7] Young Elliott, Wang language, Fantai Liang, et pear rift sedimentary characteristics YINGCHENG Sujiatun area [J] Oil and Gas Geology, 2013,34 (3): 349-356.

[8] Zhang Xi, SONG Zhen ring, Xu, et Songliao Basin rift pear dynamic evaluation of oil and gas resources $[\mathrm{J}]$ petroleum geology experiment, 2013,35 (2): 224-230.

[9] King Fu Shan, Ge Daiwei, music Jianghua, Mary Yan Yan Chan, Guangyi industry, Liu Yan, Ji Wang Xia, LI Ming Basin southeast margin sequence stratigraphy and sedimentary system configuration and evolution [J] .2013 February .31 (1): 68-76.

[10] Liang Yang pear breaking research [J] Ssangyong second concave depression reservoir characteristics and hydrocarbon accumulation mode Guangdong Chemical Industry, 2013,40 (22). 